\title{
QUALIDADE FISIOLÓGICA DE SEMENTES DE SOJA ORIUNDAS DE DISTINTOS ESTRATOS DA PLANTA
}

OLIVEIRA, Michelli Rodrigues de ${ }^{1}$

CARVALHO, Tereza Cristina $\mathrm{de}^{2}$

Recebido em: 2019.07.02 Aprovado em: 2021.03.29 $\quad$ ISSUE DOI: 10.3738/1982.2278.3666

\begin{abstract}
RESUMO: A qualidade de sementes de soja produzidas pode ser alterada em função da posição em que a vagem é produzida na planta. Desta forma, o presente trabalho tem por objetivo avaliar a qualidade fisiológica de sementes de soja produzidas em diferentes estratos da planta (inferior, mediano e superior), e mais o tratamento testemunha (colheita de todas as sementes produzidas na planta), logo após a colheita, aos 170 e 350 dias de armazenamento das sementes. O delineamento experimental foi em delineamento de blocos casualizados, sendo os tratamentos arranjados em esquema fatorial duplo, correspondendo a 4x3 (quatro estratos da planta e três épocas de avaliação). Para realização da pesquisa foi utilizada a cultivar de soja NS 6209, com hábito de crescimento indeterminado. As sementes foram avaliadas quanto a determinação do teor de água e massa de 1.000 sementes e pelos testes de germinação e envelhecimento acelerado. De acordo com os resultados obtidos conclui-se que o estrato de produção não influenciou a qualidade das sementes produzidas para os testes de germinação e envelhecimento acelerado. Porém a massa de mil sementes é superior para as sementes produzidas no estrato superior e mediano. O armazenamento de sementes de soja por 350 dias afetou o porcentual de germinação e vigor das sementes de forma negativa, independentemente do estrato de produção das sementes.
\end{abstract}

Palavras-chave: Glycine max, altura de inserção da vagem, vigor, germinação.

\section{PHYSIOLOGICAL QUALITY OF SOYBEAN SEEDS FROM DIFFERENT PLANT STRATEGIES}

SUMMARY: The quality of soybeans produced can be altered depending on the position in which the pod is produced in the plant. The objective of this work is to evaluate the physiological quality of soybean seeds produced in different strata of the plant (lower, middle and upper), and the control treatment (harvest of all seeds produced in the plant), after at 170 and 350 days of storage. The experimental design was a randomized complete block design, and the treatments were arranged in a double factorial scheme, corresponding to $4 \times 3$ (four plant strata and three evaluation periods). The soybean cultivar NS 6209, with an indeterminate growth habit, was used to conduct the research. The seeds were evaluated for water and mass content of 1,000 seeds and germination and accelerated aging tests. According to the results obtained it is concluded that the production stratum did not influence the quality of the seeds produced for the tests of germination and accelerated aging. However, the mass of one thousand seeds is superior for the seeds produced in the upper and middle strata. The storage of soybean seeds for 350 days affected the percentage of germination and vigor of the seeds in a negative way, regardless of the seed production stratum.

Keywords: Glycine max, height of pod insertion, vigor, germination.

\section{INTRODUÇÃO}

A planta de soja é uma aleuro-oleaginosa que possui ampla variabilidade genética, sendo caracterizada por ser uma planta de grande interesse econômico e que pode ter seu desenvolvimento e produção afetados por diversos fatores tanto bióticos como abióticos (PITTELKOW et al., 2009; SÃO MIGUEL et al., 2018; MARCOS-FILHO, 2015).

Entre os fatores determinantes para desenvolvimento da cultura da soja, destacam-se o fotoperíodo, temperatura e a disponibilidade de água, que provocam mudanças qualitativas e

\footnotetext{
${ }^{1}$ Engenheira Agrônoma. Analista de Sementes da Castrolanda - Cooperativa Agroindustrial. Castro, PR - Brasil.

2 http://orcid.org/0000-0001-9446-695X. Docente do curso de graduação em Agronomia e pós-graduação em Produção e tecnologia de sementes.
} 
quantitativas sobre a cultura (BENEDETTIA et al., 2020). No entanto, há períodos nos quais a planta é incapaz de perceber tais sinais, especialmente entre a emergência e a floração (RODRIGUES et al., 2001). Plantas de soja submetidas a temperaturas acima de $13^{\circ} \mathrm{C}$, tem maior indução a floração; entretanto, as variações de temperatura podem acarretar em maturação acelerada das sementes (EMBRAPA SOJA, 2013; MARCOS-FILHO, 2015). Já a água é importante para a planta, pois atua em vários processos fisiológicos na célula e no tecido vegetal; entre eles, a água é o mais abundante solvente, permite o movimento de moléculas na planta e as reações químicas, entre tantos outros fatores (FILLY et al., 2016), além de interferir na produtividade da planta (ARAÚJO et al., 2009).

As sementes produzidas, podem sofrer especialmente por deterioração por umidade, lesões causadas por percevejos, lesões físicas na cobertura, bem como a sanidade das sementes. Tais fatores acarretam prontamente na redução da germinação e vigor e, por consequência, a viabilidade das sementes (COSTA et al., 2003). Quando uma planta de soja se desenvolve, ela produz suas vagens distribuídas no caule, sendo estas distribuídas próximas a copa, região mediana e na região inferior da planta. As vagens irão produzir sementes, que se constituirão tecidos dreno na planta, ou seja, estruturas que irão demandar de fotoassimilados e nutrientes oriundos da planta mãe para sua maturação (TAIZ; ZEIGER, 2013; MARCOS-FILHO, 2015).

A distribuição de matéria orgânica entre os diferentes órgãos de uma planta é resultante de um conjunto de processos metabólicos e de relações hídricas, que governam o fluxo de assimilados através de um sistema fonte-dreno (KERBAUY, 2008). Quanto aos fatores que definem a força do dreno, citam-se como os principais, proximidade, desenvolvimento e conexões vasculares (HARUTA; SUSSMAN, 2012; TAIZ; ZEIGER, 2013). Em plantas de soja, as sementes produzidas no estrato superior, próximas a copa da planta, estão expostas a maior incidência dos raios solares, e as folhas próximas a ela tem maior taxa fotossintética, além da maior ventilação a que esta estrutura da planta está exposta (TEIXEIRA et al., 2015). A disponibilidade de luz em que a planta cresce é relevante, pois influência no seu aparelho fotossintético, e consequentemente no seu crescimento (ALMEIDA et al., 2004).

Já as vagens que se desenvolvem no estrato inferior, estão mais próximas a raiz, este órgão, é responsável pela absorção de água e nutrientes do solo (KERBAUY, 2008; TEIXEIRA et al., 2015). Em regiões da planta próximas ao solo, há maior incidência de microrganismos, pois a umidade relativa do ar é maior e a ventilação nesta região é menor. Este fato torna-se mais relevante a medida que a população de plantas por área é maior. Flores (2016), ao estudar o potencial fisiológico de sementes de soja provenientes de cultivares de hábitos de crescimento determinado e indeterminado, em diferentes estratos da planta (inferior, mediano e superior), 
constatou que independentemente do hábito de crescimento a qualidade fisiológica se mantem semelhante entre as sementes produzidas. Porém, sementes produzidas no estrato inferior da planta possuem menor qualidade fisiológica ao comparar com os estratos médio e superior.

Assim, o presente trabalho tem por objetivo avaliar a qualidade fisiológica de sementes de soja produzidas em diferentes estratos da planta (inferior, mediano e superior), e mais o tratamento testemunha (colheita de todas as sementes produzidas na planta), logo após a colheita, aos 170 e 350 dias de armazenamento das sementes.

\section{MATERIAL E MÉTODO}

O presente experimento foi conduzido em campo de multiplicação de sementes da Fazenda Santa Maria, no município de Castro, PR. A área localiza-se nas seguintes coordenadas geográficas: $24^{\circ} 44^{\prime} 48^{\prime}$ 'S e 4953'23'’O e altitude de 1010 metros; sendo o clima da região é do tipo Cfa, segundo a classificação de Köppen.

$\mathrm{Na}$ área experimental foi adotado o sistema de plantio direto, sendo realizada a análise e correção da fertilidade do solo de acordo com as necessidades da cultura da soja. Para a execução da pesquisa foi utilizada a cultivar de soja NS 6209, com hábito de crescimento indeterminado, da classe certificada, registrada no Registro Nacional de Cultivares (RNC). Foi realizado o acompanhamento do desenvolvimento das plantas em campo e realização de tratos culturais, requeridos pela cultura.

O delineamento experimental utilizado na pesquisa foi em blocos casualizados (DBC), adotando-se quatro tratamentos, com cinco repetições. Os tratamentos (T) foram estabelecidos pela delimitação de cada estrato, sendo as plantas medidas com auxílio de uma trena para a obtenção do comprimento total das mesmas. Calculou-se a altura média das plantas como sendo 90 centímetros. Os 90 centímetros de comprimento da altura das plantas foram divididos em 3 estratos: os primeiros 30 centímetros da planta medidos a partir da sua extremidade do meristema apical caulinar, foi considerado estrato superior (T1). Os 30 centímetros medidos do nível médio das plantas, a partir do término do estrato superior, considerou-se estrato mediano (T2); e a medição dos 30 centímetros do nível médio até a base do caule, próximo à sua raiz, considerou-se estrato inferior (T3). Para cada tratamento foram implantadas seis linhas, com $5 \mathrm{~m}$ de comprimento, sendo que uma linha de cada extremidade foi considerada como bordadura.

$\mathrm{Na}$ ocasião da colheita, dentro da área útil foram escolhidas aleatoriamente 30 plantas para colheita. As vagens foram trilhadas separadamente de acordo com cada estrato, perfazendo os três primeiros tratamentos. Para o último tratamento, realizou-se a colheita das vagens dos 90 centímetros de planta (Testemunha - T4). 
Após a colheita das sementes, foi realizada a trilhagem separadamente das sementes para cada tratamento, estas foram previamente limpas e na sequencia conduzidas para análises em laboratório. As análises das sementes foram efetuadas no Laboratório de Análise de Sementes da Castrolanda Cooperativa Agroindustrial Ltda., no município de Castro, Paraná; sendo realizadas três avaliações, a saber: logo após a colheita, aos seis meses (170 dias) e aos 12 (350) meses de armazenamento. No laboratório, as amostras pertencentes a cada tratamento e repetição foram pesadas e homogeneizadas. Na sequência, realizou-se as primeiras avaliações, que consistiam na determinação do teor de água, e na condução dos testes de germinação, envelhecimento acelerado e massa de mil sementes (BRASIL, 2009; FRANÇA NETO et al., 1998).

Após a realização das análises das sementes (logo após a colheita), as amostras foram conservadas em embalagens de caixas de papel identificadas com nome da espécie, cultivar, categoria, safra, peso da amostra média, testes submetidos, bem como: determinação do teor de água, massa de 1.000 sementes, germinação e vigor de envelhecimento acelerado.

Posteriormente, as sementes foram armazenadas por um período de 350 dias em sala de arquivo de amostras à temperatura e umidade relativa do ar controlada, as quais não ultrapassaram $20^{\circ} \mathrm{C}$ e $65 \%$ de UR. A temperatura média no ambiente climatizado durante o armazenamento foi de $20^{\circ} \mathrm{C}$, a média máxima foi de $21,4^{\circ} \mathrm{C}$, e a média mínima foi de $18,9^{\circ} \mathrm{C}$.

Aos 170 dias e aos 350 dias de armazenamento, foi realizada a segunda e a terceira avaliação da qualidade fisiológica respectivamente, através dos mesmos testes adotados anteriormente.

Para a determinação do teor de água foi adotado o método de estufa a $105 \pm 3^{\circ} \mathrm{C}$, por 24 horas, com duas amostras para cada repetição de cada tratamento (BRASIL, 2009). Os resultados foram expressos na base úmida, para cada tratamento.

Na determinação da massa de 1.000 sementes, calculou-se a variância, o desvio padrão e o coeficiente de variação dos valores obtidos das pesagens das sementes. Assim foram pesadas oito repetições de 100 sementes, na sequência, obtendo-se a média entre as oito repetições e multiplicando-as por 10, a fim de ter a massa de 1.000 sementes (BRASIL, 2009).

Já no teste de germinação foram utilizadas duas subamostras de 50 sementes por repetição, para cada tratamento. As sementes foram distribuídas em rolos de papel umedecidos com água em quantidade equivalente a 2,5 vezes a massa do substrato, e levados ao germinador à temperatura de $25^{\circ} \mathrm{C}$, por cinco dias, com luminosidade constante. Os resultados foram expressos em porcentagem, aos cinco dias após a semeadura, através da análise das plântulas consideradas normais (BRASIL, 2009). 
No teste de envelhecimento acelerado, as sementes foram distribuídas de maneira uniforme e camada única, em caixa plástico tipo gerbox contendo $40 \mathrm{~mL}$ de água destilada e submetidas à alta temperatura $\left(41^{\circ} \mathrm{C}\right)$, por 48 horas em incubadora BOD. Posteriormente, com estas sementes foi instalado o teste de germinação, similar ao procedimento escrito no item "teste de germinação". Ao final de cinco dias realizou-se a contagem das plântulas normais (BERTOLIN et al., 2010).

$\mathrm{Na}$ realização do procedimento estatístico, fez-se a adoção de fatorial duplo (4x3), sendo o primeiro fator o estrato da planta (superior, mediano, inferior e planta inteira) e o segundo fator as épocas de avaliação (logo após a colheita e aos 170 e 350 dias após o armazenamento). As médias foram comparadas pelo teste de Tukey a $\mathrm{p} \leq 0,05$. Quando houve interação das épocas de armazenamento em cada estrato, realizou-se a análise em regressão. Todos os dados foram computados e inseridos no Excel visando gerar as tabelas e os gráficos; sendo a análise estatística realizada por meio do programa RStudio (2019).

\section{RESULTADO E DISCUSSÃO}

Os resultados para o grau de umidade das sementes para os estratos, foi de: estrato superior de $11,6 \%$, mediano de $10,1 \%$ e inferior de $10,4 \%$. Por meio destes valores, observa-se que a diferença entre o menor e maior valor é de 1,5\%. Essa variação é pequena, não interferindo na confiabilidade dos resultados gerados nos testes feitos (MARCOS-FILHO, 2015). Para cada época em que se determinou o grau de umidade das sementes, seja logo após a colheita ou aos 170 e 350 dias após o armazenamento, a oscilação máxima do grau de umidade não foi superior a $1,0 \%$, para todos os tratamentos.

Analisando os valores porcentuais para o teste de germinação das sementes de soja entre os estratos (Tabela 1), não se verificou diferenças estatísticas, quando se analisou o efeito do estrato de produção das sementes de soja, isoladamente em cada época de avaliação. Tal fato evidencia que a localização de formação das sementes na planta não afeta a germinação das sementes, independentemente se esta variável é analisada logo após a colheita ou aos 170 e 350 dias após o armazenamento. 
Tabela 1. Dados médios de germinação obtidos de sementes, oriundas de distintos estratos de plantas de soja, logo após a colheita, aos 170 e 350 dias após o armazenamento. Castro, Paraná, 2019.

\begin{tabular}{|c|c|c|c|}
\hline \multirow{2}{*}{ Estrato } & \multicolumn{3}{|c|}{ Época de avaliação (dias após o armazenamento) } \\
\hline & 0 & 170 & 350 \\
\hline & \multicolumn{3}{|c|}{------------------------------ $\%$------------------------------ } \\
\hline $\begin{array}{l}\text { Superior } \\
\text { (T1) } \\
\text { Mediano }\end{array}$ & 93 & 88 & 83 \\
\hline $\begin{array}{l}\text { (T2) } \\
\text { Inferior }\end{array}$ & 92 & 86 & 80 \\
\hline $\begin{array}{l}\text { (T3) } \\
\text { Inteira }\end{array}$ & 93 & 88 & 81 \\
\hline (T4) & 92 & 88 & 82 \\
\hline C.V. $(\%)$ & \multicolumn{3}{|c|}{$3,02^{\text {N.S. }}$} \\
\hline
\end{tabular}

Médias seguidas na coluna não diferem entre si pelo teste de Tukey a $p \leq 0,05$.

Fonte: Elaborado pelos Autores

Segundo a Instrução Normativa $\mathrm{n}^{\circ}$ 45, de 17 de setembro de 2013, o padrão mínimo de germinação para a comercialização de sementes certificadas é de $80 \%$, sendo que as sementes que estão abaixo deste padrão não podem ser comercializadas como sementes (BRASIL, 2013). Desta forma, os resultados obtidos evidenciam a produção de sementes cuja germinação encontram-se aptas para a comercialização, estando em conformidade com o padrão regido pelo Ministério da Agricultura, Pecuária e Abastecimento.

Com relação ao comportamento médio da germinação em ambos os estratos de produção das sementes na planta, ao longo do período de armazenamento (Figura 1), observa-se a redução do potencial germinativo para ambos os estratos avaliados (superior, mediano, inferior e planta inteira) em função do tempo de armazenagem, desde a colheita até os 350 dias de armazenamento. Em condições de armazenamento em temperatura de $20^{\circ} \mathrm{C}$ e umidade relativa inferior a $65 \%$, o menor valor de germinação registrado foi de $80 \%$ (Tabela 1). 
Figura 1. Dados médios de germinação obtidos de sementes oriundas de distintos estratos de plantas de soja, logo após a colheita e aos 170 e 350 dias após o armazenamento. Castro, Paraná, 2019.

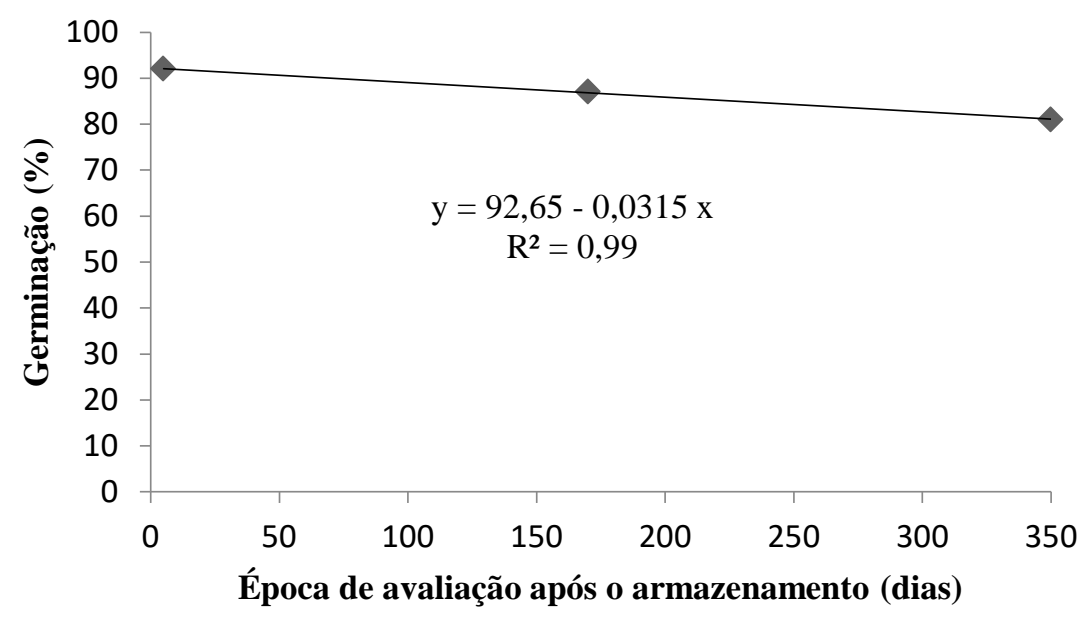

Fonte: Elaborado pelos Autores

O conhecimento do período que pode ser realizado o armazenamento das sementes, de forma a manter a germinação mínima exigida, é importante para fins na tomada de decisão do período de armazenamento adequado. Esse fato torna-se mais relevante a medida que ocorre variações no ambiente do armazém e também quando as sementes possuem teores de água mais elevados. Quando o grau de umidade das sementes é acima de $14,0 \%$, isso afeta a qualidade do material em função da deterioração mais acelerada das sementes (SMANIOTTO et al., 2014).

Zucareli et al. (2015) analisaram a qualidade fisiológica de sementes de feijão através de testes de germinação e vigor, e verificaram que os lotes de sementes apresentam redução da qualidade, principalmente quando expostos a condições de ambiente não controladas.

Do mesmo modo, Juvino et al. (2014) obtiveram resultados positivos para um período de armazenamento de nove meses para sementes de soja, sendo que as sementes continuaram a apresentar porcentuais de germinação e vigor elevados. Entretanto, a manutenção da qualidade das sementes depende da climatização do ambiente de armazenagem e do teor de água (MARCOS-FILHO, 2015).

É imprescindível a atuação do controle de qualidade na produção de sementes de soja, assegurando a qualidade do material produzido desde a implantação da cultura em campo até a sua comercialização. Assim, não basta apenas o monitoramento da lavoura e estande, mas também a supervisão durante o beneficiamento, objetivando reduzir impactos mecânicos nas sementes durante o processo ou durante a etapa de colheita.

Ao analisar os resultados referentes ao vigor de sementes de soja pelo teste de envelhecimento acelerado (Tabela 2), verifica-se que a viabilidade das sementes não é 
influenciada pelo estrato de produção na planta, o que pode ser um indício que as diferenças de vigor das sementes produzidas numa mesma planta são muito sutis. De acordo com MARTINS et al. (2014), sementes com potencial máximo de vigor podem estar associadas às diferenças de genótipos.

Tabela 2. Dados médios de envelhecimento acelerado obtidos de sementes de soja, oriundas de distintos estratos da planta, logo após a colheita, aos 170 e 350 dias após o armazenamento. Castro, Paraná, 2019.

\begin{tabular}{|c|c|c|c|}
\hline \multirow{2}{*}{ Estrato } & \multicolumn{3}{|c|}{ Época de avaliação (dias após o armazenamento) } \\
\hline & 0 & 170 & 350 \\
\hline & \multicolumn{3}{|c|}{ 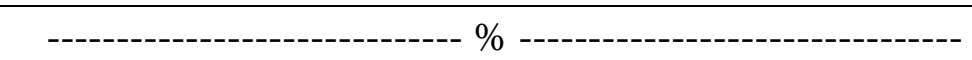 } \\
\hline Superior (T1) & 89 & 83 & 76 \\
\hline Mediano (T2) & 91 & 86 & 79 \\
\hline Inferior (T3) & 90 & 85 & 77 \\
\hline Inteira (T4) & 90 & 86 & 80 \\
\hline C.V. $(\%)$ & \multicolumn{3}{|c|}{$3,46^{\text {N.S. }}$} \\
\hline
\end{tabular}

Médias seguidas na coluna não diferem entre si pelo teste de Tukey a $\mathrm{p} \leq 0,05$.

N.S. Não significativo

Fonte: Elaborado pelos Autores

Da mesma forma que para germinação, o período de armazenamento influenciou o vigor das sementes, quando analisado pelo teste de envelhecimento acelerado dos quatro estratos avaliados (superior, mediano, inferior e planta inteira) (Figura 2). Uma vez que à medida que se aumenta o período de armazenamento, os valores médios para vigor decrescem (Figura 2).

Figura 2. Dados médios de envelhecimento acelerado obtidos de sementes, oriundas de distintos estratos de plantas de soja, logo após a colheita, aos 170 e 350 dias após o armazenamento. Castro, Paraná, 2019.

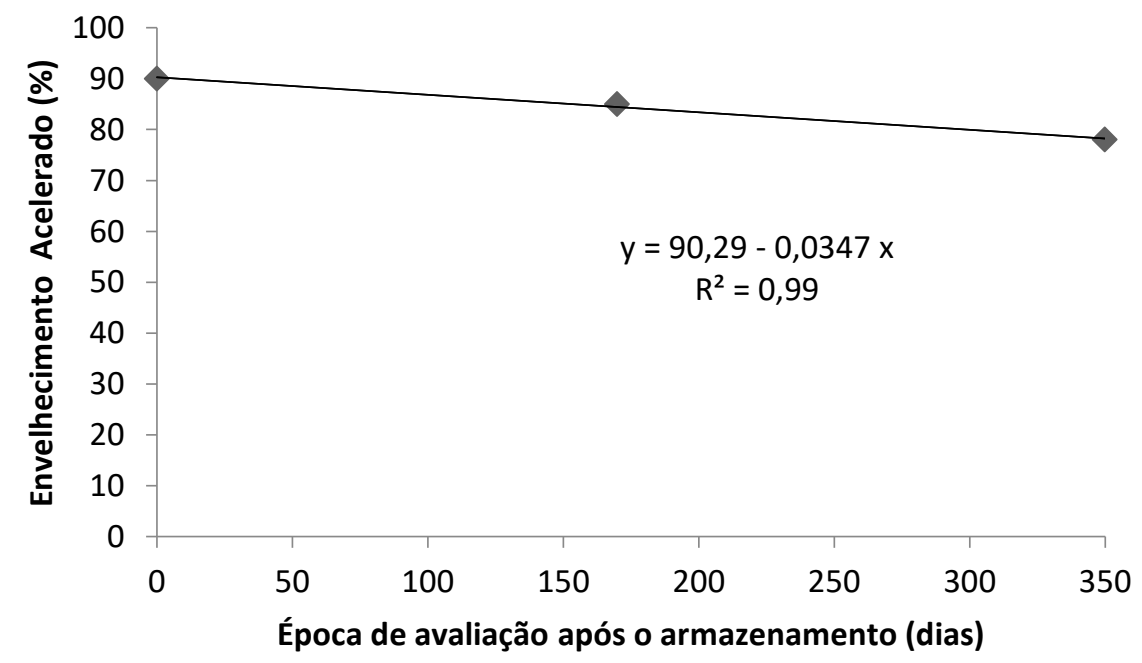

Fonte: Elaborado pelos Autores

Nucleus, v.18, n.1, abr. 2021 
Tal fato pode estar relacionado com a atividade respiratória das sementes, que mesmo de forma mais lenta, contribui na redução da massa fresca dos tecidos de reserva e podem reduzir o vigor (MARCOS-FILHO, 2015). A ocorrência de fungos de armazenamento, embora não analisada, pode contribuir na queda da germinação e vigor dos lotes de sementes produzidos. Rocha et al. (2014), comprovaram através de teste de vigor de comprimento de plântula que lotes de sementes de soja infectados pelo fungo Aspergillus ochraceus com incidência acima de 50\% apresentam grandes perdas de vigor e deterioração dos seus tecidos. Desta forma, o tratamento de sementes é de extrema importância para a viabilidade das mesmas (PEREIRA et al., 2017).

A tecnologia de produção de sementes vem aprimorando cada vez mais o desenvolvimento de procedimentos que avaliam a qualidade fisiológica, bem como o vigor do material produzido. Isso é justificado pela importância da velocidade de emergência e uniformidade das plântulas em um campo de produção de sementes. Assim, o teste de vigor de envelhecimento acelerado em condições de $41^{\circ} \mathrm{C}$ durante 24 horas em sementes de soja, é considerado sensível à avaliação das sementes, sendo um dos testes mais aplicados e indicados para a análise de sementes de soja em condições de armazenamento (MARCOS FILHO et al., 2009).

Quando se analisou a massa de mil sementes dos distintos estratos, observou-se influência da massa de acordo com o local de produção na planta (Tabela 3). Assim, as sementes produzidas no estrato inferior, possuem menor massa de mil sementes quando comparadas às sementes oriundas dos estratos superior e mediano das sementes. Tal observação foi constatada logo após a colheita, como aos 170 e 350 dias após o armazenamento (Tabela 3). Já para as sementes colhidas em conjunto em toda a planta, verificou-se um comportamento intermediário no que diz respeito a massa de mil sementes (Tabela 3). Este fato pode ter ocorrido em decorrência na homogeneização das sementes de maior massa, com as de menor massa.

A produção das sementes, oriundas de vagens inseridas ao estrato mediano e superior da planta, estão mais expostas à incidência dos raios solares, possibilitando maior translocação de fotoassimilados em direção a elas. Isso se ocorre quando se leva em consideração a rota de translocação fonte-dreno proximidade (KERBAUY, 2008; HARUTA; SUSSMAN, 2012; TAIZ; ZEIGER, 2013). Entretanto, de acordo com Flores (2016), plantas de soja com hábito de crescimento indeterminado favorecem a ocorrência de sementes de maiores tamanhos e maior rendimento por toda a extensão da planta. 
Tabela 3. Dados médios da massa de mil sementes obtidos de sementes de soja, oriundas de distintos estratos da planta, logo após a colheita, aos 170 e 350 dias após o armazenamento. Castro, Paraná, 2019.

\begin{tabular}{ccccc}
\hline \multirow{2}{*}{ Estrato } & & \multicolumn{3}{c}{ Época de avaliação (dias após o armazenamento) } \\
\cline { 3 - 4 } & & 0 & 170 & 350 \\
\cline { 3 - 4 } & & $202,0 \mathrm{a}$ & $202,0 \mathrm{a}$ & $202,0 \mathrm{a}$ \\
Superior (T1) & & $203,0 \mathrm{a}$ & $202,0 \mathrm{a}$ & $202,0 \mathrm{a}$ \\
Mediano (T2) & $186,0 \mathrm{~b}$ & $186,0 \mathrm{~b}$ & $185,0 \mathrm{~b}$ \\
Inferior (T3) & $190,0 \mathrm{ab}$ & $190,0 \mathrm{ab}$ & $189,0 \mathrm{ab}$ \\
Inteira (T4) & & \multicolumn{3}{c}{7,26} \\
\cline { 3 - 4 } & & &
\end{tabular}

Médias seguidas de mesma letra na coluna não diferem entre si pelo teste de Tukey $\mathrm{p} \leq 0,05$.

Fonte: Elaborado pelos Autores

Não houve diferenças estatísticas para a avaliação de massa de mil sementes em função do tempo de armazenamento, independentemente se a avaliação ocorreu logo após a colheita ou com o passar do período de armazenamento. Provavelmente as condições de armazenamento $\left(20^{\circ} \mathrm{C}\right.$ e $65 \%$ UR ar), foram favoráveis para manter a massa seca das sementes a ponto de não gerar diferenças significativas entre os distintos períodos de armazenamento avaliados.

Os resultados obtidos demonstram que a formação de sementes nos distintos estratos de produção da planta não interfere a qualidade de semente para os testes de germinação e vigor de envelhecimento acelerado. Porém quando se analisa o tempo de armazenamento das sementes, para ambos os testes de germinação (Tabela 1 e Figura 1) e envelhecimento acelerado (Tabela 2 e Figura 2), estes têm seu porcentual reduzidos em função da queda da qualidade, com o aumento do período de armazenagem. Isto justifica a importância do condicionamento adequado das sementes e da comercialização das sementes dentro do período de validade dos lotes.

\section{CONCLUSÃO}

A germinação das sementes de soja, bem como o vigor obtido pelo teste de envelhecimento acelerado não são alterados de acordo com estrato de produção das sementes na planta (inferior, mediano, superior ou planta inteira). Porém ambos tendem a serem reduzidos à medida que o período de armazenamento se estende por 350 dias.

Há superioridade na massa das sementes produzidas nos estratos superior e mediano, em comparação as sementes produzidas no estrato inferior ou quando avaliado as sementes oriundas de toda a planta. O período de armazenamento de 350 dias, não interferiu nesta variável, independente do estrato analisado. 


\section{REFERÊNCIAS}

ALMEIDA, L.P.; ALVARENGA, A.A.; CASTRO, E.M.; ZANELA, S.M.; VIEIRA, C.V. Crescimento inicial de plantas de Cryptocaria aschersoniana Mez. submetidas a níveis de radiação solar. Ciência Rural, Santa Maria, v.34, n.1, p.83-88, 2004.

ARAUJO, M. A.; SOUZA, J. L.M.; BRONDANI, G.E.; PAULETTI, V. Sistemas de manejo e relações hídricas do solo na produtividade da cultura da soja, em Ponta Grossa-Paraná. Scientia agraria, Piracicaba, v. 10, n. 5, 2009.

BENEDETTIA, L.; SCHERNERB, A.; CUCHIARAC, C.C.; MORAESD, I.L.; AVILAA, L.A.; DEUNERA, S. Soybean plant osmotic and oxidative stress as affected by herbicide and salinity levels in soil. Planta Daninha, v.38, p.1-7, 2020.

BERTOLIN, D. C.; SÁ, M. E. D.; MOREIRA, E. R. Parâmetros do teste de envelhecimento acelerado para determinação do vigor de sementes de feijão. Revista Brasileira de Sementes, Londrina, p. 104-112, 2011.

BRASIL. Ministério da Agricultura, Pecuária e Abastecimento. Regras para Análise de Sementes. Brasília: Secretaria de Defesa Agropecuária, MAPA/ACS, 2009. 398p.

CHUNG, G.; SINGH, R.J. Broadening the genetic base of soybean: a multidisciplinary approach. Critical Reviews in Plant Sciences, v. 27, n. 5, p. 295-341, 2008.

COSTA, N.P.D.E.S.; MESQUITA, C.D.M.E.S., MAURINA, A.C., FRANÇA-NETO, J.B.; KRZYZANOWSKI, F.C.E.S., HENNING, A.A.E.S. Qualidade fisiológica, física e sanitária de sementes de soja produzidas no Brasil. Revista Brasileira de Sementes, Londrina, v.25, n.1, p.128-132, 2003.

EMBRAPA SOJA. Tecnologias de Produção de Soja - Região Central do Brasil 2014. Londrina: Embrapa Soja, 2013. 265p. Disponível em: < https://ainfo.cnptia.embrapa.br/digital/bitstream/item/95489/1/SP-16-online.pdf $>$. Acesso em: 21 fev. 2019.

FILLY, A.; TIXIER, A.S.F.; LOUIS, C.; FERNANDEZ, X.; CHEMAT, F. Water as a green solvent combined with different techniques for extraction of essential oil from lavender flowers. Comptes Rendus Chimie, v.19, n.6, p.707-717, 2016.

FLORES, M. F. Qualidade fisiológica e rendimento de sementes de soja em função do hábito de crescimento da planta. 2016. 59 f. Tese (Doutorado) - Curso de Agronomia, Área de Concentração em Produção Vegetal, Universidade Federal do Paraná, Curitiba, 2016.

HARUTA, M.; SUSSMAN, M.R. The effect of a genetically reduced plasma membrane protonmotive force on vegetative growth of Arabidopsis. Bioenergetics and photosynthesis, v.158, p. 1158-117, 2012.

JUNIOR ZANON, A.; MINUSSI WINCK, J.E.; STRECK, N.A.; MARQUES DA ROCHA, T.S.; CEOLIN CERA, J.; RICHTER, G.L.; MARCHESAN, E. Desenvolvimento de cultivares de soja em função do grupo de maturação e tipo de crescimento em terras altas e terras baixas. Bragantia, Campinas, v. 74, n. 4, p.400-411, 2015. 
JUVINO, A.N.; RESENDE, O.; COSTA, L.M.; SALES, J.F. Vigor da cultivar BMX Potência RR de soja durante o beneficiamento e períodos de armazenamento. Revista Brasileira de Engenharia Agrícola e Ambiental, Campina Grande, v. 18, n. 8, 2014.

KERBAUY, G.B. Fisiologia vegetal. Rio de Janeiro: Guanabara Koogan, 2008. 431 p.

MAPA. Ministério da Agricultura, Pecuária e Abastecimento. Brasil. Instrução Normativa no 45. 17 de setembro de 2013. Estabelece padrões de identidade e qualidade para a produção e a comercialização de sementes. DOU de 20/09/2013 (nº 183, Seção 1, pág. 6). 2013.

MARCOS-FILHO, J. Fisiologia de sementes de plantas cultivadas. Londrina: ABRATES, 2015. 659p.

MARCOS-FILHO, J. Importância do potencial fisiológico da semente de soja. Informativo Abrates, Londrina, v. 23, n. 1, p. 21-23, 2013.

MARCOS-FILHO, J., KIKUTI, A.L.P.; LIMA, L.B.D. Métodos para avaliação do vigor de sementes de soja, incluindo a análise computadorizada de imagens. Revista Brasileira de Sementes, Londrina, v. 31, n. 1, p. 102-112, 2009.

PEREIRA, C.E., PEREIRA, M.C., BRITO JÚNIOR, J.G.; CRUZ MACHADO, J. Sementes de soja infectadas por Cercospora kikuchii, sob déficit hídrico. Científica, v. 45, n. 3, p. 295-299, 2017.

PITTELKOW F.K.; JAKELAITIS, A.; CONUS, LA.; OLIVEIRA, A.A.; GIL, J.O.; ASSIS, F.C.; BORCHARTT, L. Interferência de plantas daninhas na cultura da soja transgênica. Global Science and Technology. v.02, p. 38-48, 2009.

REIS BARBOSA, C.Z.D.; SMIDERLE, O.J.; ARCANJO ALVES, J.M.; ALCANTARA VILARINHO, A.; SEDIYAMA, T. Qualidade de sementes de soja BRS Tracajá, colhidas em Roraima em função do tamanho no armazenamento. Revista Ciência Agronômica, Ceara, v. 41, n. 1, p.73-80, 2010.

RODRIGUES, O.; DIDONET, A. D.; LHAMBY, J. C. B.; BERTAGNOLI, P. F.; LUZ, J. S. Resposta quantitativa do florescimento da soja à temperatura e ao fotoperíodo. Pesquisa Agropecuária Brasileira, Brasília, v. 36, n. 3, p. 431-437, 2001.

RSTUDIO. Undelete and data recovery software. Software livre de ambiente de desenvolvimento integrado para R para análises estatísticas. Versão obtida em: 10 nov. 2019. Disponível em: https://www.rstudio.com/

SÃO MIGUEL, A.S.D.C.; PACHECO, L.P.; SOUZA, E.D.; SILVA, C.M.R.; CARVALHO, Í.C. Cover crops in the weed management in soybean culture. Planta Daninha, Viçosa, v.36, p.1-10, 2018.

SILVA ROCHA, F.; RODRIGUES MOREIRA CATÃO, H. C.; BRANDÃO, A.A.; AUGUSTO GOMES, L.A. Danos causados por diferentes potenciais de inóculo de Aspergillus ochraceus no vigor de sementes de soja. Semina: Ciências Agrárias, Londrina, v. 35, n. 6, p. 2895-2904, 2014. 
SMANIOTTO, T.D.S.; RESENDE, O.; MARÇAL, K.A.; OLIVEIRA, D.D.; SIMON, G.A. Qualidade fisiológica das sementes de soja armazenadas em diferentes condições. Revista Brasileira de Engenharia Agrícola e Ambiental, Campina Grande, v. 18, n. 4, p. 446-453, 2014.

TAIZ, L.; ZEIGER, E. Fisiologia Vegetal. 5a edição, Porto Alegre: Artmed Editora, 2013. 918p.

TEIXEIRA, G.C.S.; STONE, L.F.; HEINEMANN, A.B. Eficiência do uso da radiação solar e índices morfofisiológicos em cultivares de feijoeiro. Pesquisa Agropecuária Tropical, v.45, n.1, p.9-17, 2015.

ZUCARELI, C.; BRZEZINSKI, C.R.; ABATI, J.; WERNER, F.; RAMOS JÚNIOR, E.U.; NAKAGAWA, J. Qualidade fisiológica de sementes de feijão carioca armazenadas em diferentes ambientes. Revista Brasileira de Engenharia Agrícola e Ambiental, Campina Grande, v. 19, n. 8, p.803-809, 2015. 